\title{
Targeting Antibacterial Effect and Promoting of Skin Wound Healing After Infected with Methicillin-Resistant Staphylococcus aureus for the Novel Polyvinyl Alcohol Nanoparticles
}

\section{Dengyan $\mathrm{Wu}^{\mathrm{l}}$ \\ Dong $\mathrm{Wei}^{2}$ \\ Maotao Du' \\ Song Ming \\ Qian Ding' \\ Ranjing Tan'}

'Department of Dermatology, Second affiliated Hospital, Chongqing Medical University, Chongqing, 4000 I0, People's

Republic of China; ${ }^{2}$ Plastic Surgery, Pengshui County People's Hospital, Pengshui, 409600,

People's Republic of China

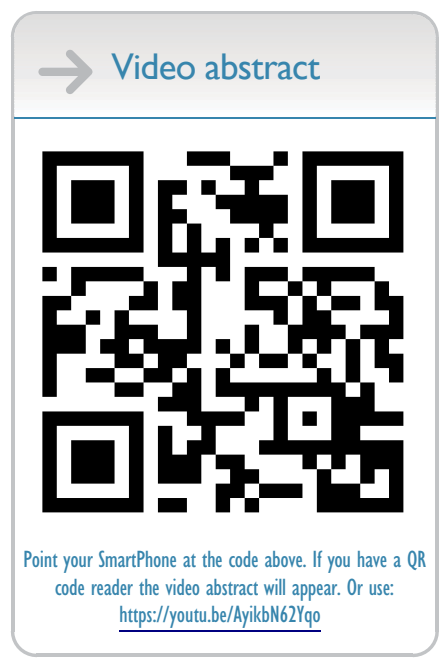

Correspondence: Ranjing Tan Department of Dermatology, Second affiliated Hospital, Chongqing Medical University, Chongqing, 4000 I0, People's Republic of China

Email starrynightjing@I63.com

\begin{abstract}
Introduction: Topical agents typically remain in the wound site for time duration that are too short to effectively eradicate MRSA tradition formation of BZK that can be maintained within the wound site for longer time periods, should be more effective.

Methods: The novel chitosan and poly (D,L-lactide-co-glycoside) nanoparticles loaded with benzalkonium bromide (BZK) were designed, for the promotion wound healing after MRSA infection. The physical characterization of these nanoparticles, as well as their antibacterial activity in vitro, release profile in simulated wound fluid, cell toxicity, anti-biofilm activity, and their ability to improve the skin wound healing in a mouse model were also studied.

Results: These novel nanoparticles were found to have a significant antibacterial activity $(p<0.01)$, both in vitro and in vivo test. The stronger anti-biofilm ability of the nanoparticles to inhibit the formation of bacterial biofilms, at a concentration of $3.33 \mu \mathrm{g} / \mathrm{mL}$, and clear existing bacterial biofilms, at a concentration of $5 \mathrm{mg} / \mathrm{mL}$, compared with its water solution. In addition, significant damage to bacterial cell walls also was found, providing insight into the mechanism of antibacterial activity.

Conclusion: Taken together, these results demonstrated the ability of BZK-loaded nanoparticles in the promotion of skin wound healing with MRSA infection. The current findings open a new avenue for nanomedicine development and future clinical applications in the treatment of wounds.
\end{abstract}

Keywords: MRSA, wound, nanoparticles, antibacterial effect, biofilm

\section{Introduction}

Wounds represent a serious, and often overlooked, health problem in the global world. Importantly, if left untreated, several complications arise including infection, amputation, and long-term morbidity. ${ }^{1}$ The wound treatment has placed a massive financial burden on the health-care system, with serious and disturbing consequences for the affected patients. ${ }^{2}$ The development of new treatments that enhance the wound healing process and prevent, or limit, scarring is needed. ${ }^{3}$ Impaired wound healing is characterized by a loss of synchronization of the molecular interactions required for skin tissue repair. ${ }^{4}$ Six million patients a year are affected by wounds, costing the health-care system an estimated $\$ 25$ billion dollars. ${ }^{4}$ Wound infection is the most common impediment to wound healing, leading to increase the morbidity and mortality among patients. ${ }^{5}$ The crisis of antimicrobial resistance is 
worsening, and the world is living in a post-antibiotic era in which common infections, and previously treatable wounds, can once again result in death. ${ }^{6}$ To accelerate wound healing and promote the cell proliferation, proper cleaning and swab treatment of infections are important measures in wound care. ${ }^{4}$ Staphylococcus aureus is the most common bacterial pathogen in wound sites, and the presence of methicillin-resistant Staphylococcus aureus (MRSA) multiply the risk of wound treatment failure. Biofilm formation is thought to be an important factor in reducing the penetration of antibiotics, leading to increased infection and a reduction in wound healing. ${ }^{7,8}$ Although vancomycin is currently used to treat MRSA infections, the emergence of resistant strains has increased the urgency to develop new antibiotics for the treatment of infected skin wounds. ${ }^{9}$

Recent reports have identified nanomedicine as an ideal approach to improve the efficiency and wound treatment. ${ }^{3}$ Nanoparticles are ultrafine particles between $1-1000 \mathrm{~nm}$ in diameter, ${ }^{8}$ that have many advantageous properties related to trauma therapy, including being biodegradable, exhibiting controlled drug release, enough drug delivery efficacy,${ }^{10}$ have healing properties, penetrated blood-brain barrier ${ }^{11}$ and their ability to be used as an extracellular matrix material. ${ }^{3}$ Many studies have shown that nanoparticles can improve antibacterial and wound-healing activities. ${ }^{9}$ Specifically, their ability to enhance the penetration of antibacterial agents into deeper areas of the biofilm can improve the efficacy of drugs, avoid inactivation of the biofilm matrix, effectively target infectious cells, and significantly increase the local concentration of antibiotics around bacterial cells. $^{12}$

Previous studies reported that benzalkonium bromide (BZK) can effectively inhibit MRSA, and current applications include the optimization of topical treatments in the form of nanoscale films, ${ }^{13-15}$ foams, ${ }^{15}$ sponges, ${ }^{16}$ and hydrogels. ${ }^{15,17-20}$ However, topical agents typically remain in the wound site for time durations that are too short to effectively eradicate MRSA of BZK that can be maintained within the wound site for longer time periods, should be more effective. $^{8}$

Herein we describe a novel formulation of chitosan and poly (lactic-co-glycolic acid) (PLGA) nanoparticles, loaded with benzalkonium bromide (BZK). The nanoparticles have been characterized in a series of in vitro experiments to establish their physical and chemical properties, and antibacterial activity in MRSA biofilms are examined in Figure 1. In addition, we evaluated the nanoparticles using an MRSA activated mouse model, to establish their efficacy in wound healing in vivo.

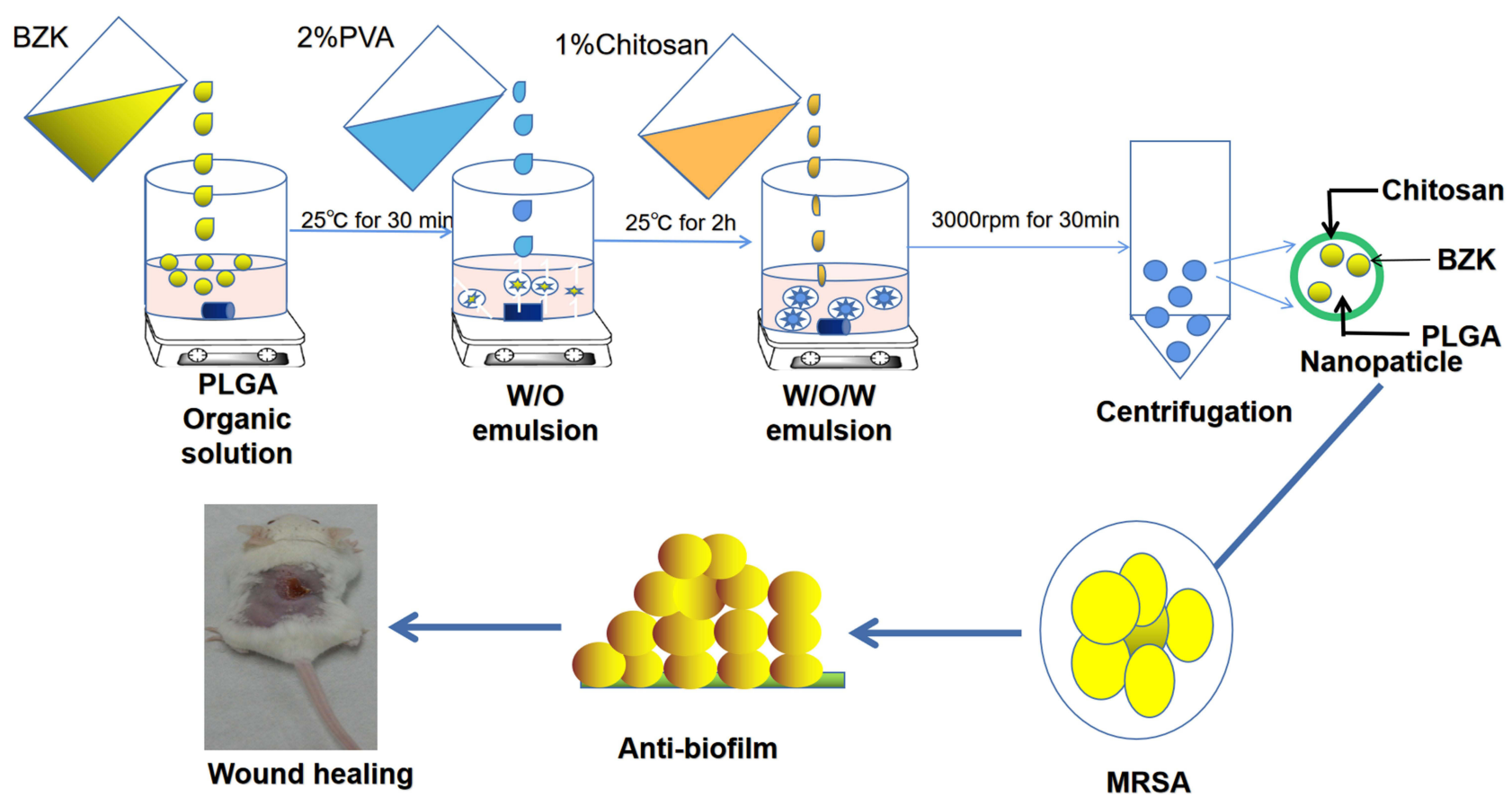

Figure I Schematic diagram showing the preparation of novel antibacterial nanoparticles. This nanoparticle can effectively inhibit the antibacterial effect of methicillinresistant Staphylococcus aureus, improve the ability of inhibit biofilm formation and clean biofilm, and thus promote the skin wound healing. 


\section{Materials and Methods \\ Materials}

Poly(D,L-lactide-co-glycoside) (PLGA, lactide/glycoside $=50 / 50$, molecular weights) and poly vinyl alcohol (8790\% hydrolyzed, molecular weights 30,000-70,000 Da, PVA) were obtained from Sigma-Aldrich (St. Louis, MO, USA). MRSA 252 was obtained from ATCC (Manassas, Virginia, USA). Muller Hinton broth (MHB), MuellerHinton Agar (MHA), and tryptic soy broth (TSB) were purchased from AOBOX Biotechnology (Beijing, People's Republic of China). Biofilm was prepared by adding $0.5 \%$ glucose and $2.0 \% \mathrm{NaCl}$ to $\mathrm{TSB}$, and an optical density (OD) value of 1.0 at $595 \mathrm{~nm}$ was defined as $1 \times 10^{9} \mathrm{CFU} /$ $\mathrm{mL}$. Female-specific pathogen-free $\mathrm{BALB} / \mathrm{C}$ mice $(6-8$ weeks old) were purchased from Beijing HFK Biotechnology Co., LTD (Beijing, PRC). Animal testing was approved by the Laboratory Animal Welfare and Ethics Committee of the Chongqing Medical University, and conducted in accordance with the Guidelines for the Care and Use of Experimental Animals. To reduce pain, mice were anesthetized with isoflurane. During the period of the experiment, all mice were fed the individual ventilated cage and kept under standard housing conditions (12-h lighting/dark cycle, $22-24^{\circ} \mathrm{C}$ room temperature, $40-60 \%$ room humidity, free drink and food were provided).

\section{Fabrication and Preparation of the BZK Nanoparticles}

Nanoparticles were prepared by solvent evaporation from an oil-water emulsion, as described previously. ${ }^{21}$ Briefly, $100 \mathrm{mg}$ of PLGA (50:50, Sigma-Aldrich, USA) was dissolved in $4 \mathrm{~mL}$ of dichloromethane (Chongqing Chuandong Chemical Co., Ltd, Chongqing, China) and poured into $20 \mathrm{~mL}$ of a $1 \%(\mathrm{~W} / \mathrm{W})$ poly(vinyl alcohol) (PVA, Sigma-Aldrich, USA) and $0.2 \%$ sodium polyphosphate (Bella Biology, China) in distilled water. Next, $5 \mathrm{mg}$ of BZK was added to the solution to generate BZKimbedded PLGA nanoparticles. PVA, which is a nonionic and hydrophilic polymer, was used as a stabilizer for the dispersion of PLGA. To coat chitosan (Sigma-Aldrich, USA) onto the PLGA nanoparticles, we prepared chitosan solution in $1 \%(\mathrm{~W} / \mathrm{W})$ acetic acid (Chongqing Chuandong Chemical Co., Ltd, Chongqing, China) and then added it to the nanoparticles solution with magnetic stirring for $8 \mathrm{~h}$ at $800 \mathrm{rpm}$, after which the chitosan-coated nanoparticles were collected. The nanoparticles were washed three times with deionized water and then lyophilized overnight. The mixture was treated with ultrasound at a power of 150 $\mathrm{W}$ for $90 \mathrm{~s}$ and stirred in the ice slurry at $550 \mathrm{rpm}$ for $4 \mathrm{~h}$, to remove dichloromethane by evaporation. Finally, BZK nanoparticles $(5 \mathrm{mg} / \mathrm{mL})$ were collected and suspended in $1 \mathrm{~mL}$ PBS (0.1M, pH 7.4) after solvent evaporation, centrifuged, and washed twice $(20,000 \times \mathrm{g}, 30$ minutes $)$ with distilled water.

\section{Characterization of Nanoparticles}

The morphology of the nanoparticles was characterized using transmission electron microscopy (TEM; FEI TECNAI10, Philips Electron Optics, Netherlands). The nanoparticles were treated ultrasonically for 20 minutes using the Ultrasonic Cleaner (power, $220 \mathrm{~W}$; frequency, $60 \mathrm{MHz}$; VWR International, Radnor, PA), and then deposited on 100 mesh with a carbon support film (Ted Pella, Redding, CA) on the copper grid. Prior to TEM observation, the samples were dried in a fume hood for 10 minutes. A scanning electron microscope (S-3400N SEM, Carl Zeiss, Germany) was used to study the morphology of the nanoparticles. Nano ZS (Malvern Instruments, UK) was used to measure the particle size and Zeta potential of BZK nanoparticles. The drug load and loading efficiency of nanoparticles were measured and calculated using high-performance liquid chromatography (HPLC; NOA 280i, GE Analytical Instruments, Boulder, $\mathrm{CO}$, USA), on an Agilent C18 column (4.6 mm $\times 250 \mathrm{~mm}$, $5 \mu \mathrm{m})$. The mobile phase was $0.07 \mathrm{~mol} / \mathrm{L}$ ammonium acetate (containing $1 \%$ triethylamine) - acetonitrile (30:70, $\mathrm{pH} 3.0 \pm 0.1$ ) after centrifuging at 13,000 rpm for $20 \mathrm{~min}$. The detection wavelength was $262 \mathrm{~nm}$, the flow rate was $1.0 \mathrm{~mL} / \mathrm{min}$, and the injection volume was $10 \mathrm{uL}$. The encapsulation efficiency (EE) and the loading capacity (LC) were calculated using the following formulas: $\mathrm{EE}=$ $(\mathrm{A}-\mathrm{B}) / \mathrm{A} \times 100 ; \mathrm{LC}=(\mathrm{A}-\mathrm{B}) / \mathrm{C} \times 100$. Where $\mathrm{A}$ is the total amount of BZK, $\mathrm{B}$ is the free amount of $\mathrm{BZK}$, and $\mathrm{C}$ is the PLGA BZK nanoparticles weight. ${ }^{22}$ These measurements were performed three times.

\section{In vitro Release in Simulated Wound Fluid}

The BZK release profile of nanoparticles was analyzed using HPLC, by the same method described above, except the medium used was simulated wound fluid (SWF). SWF (w/w) is composed of $0.64 \% \mathrm{NaCl}, 0.22 \% \mathrm{KCl}, 2.5 \%$ $\mathrm{NaHCO}_{3}$, and $0.35 \% \mathrm{NaH}_{2} \mathrm{PO}_{4}$ with the $\mathrm{pH}$ adjusted to 7.4. For all samples, the BZK concentrations were 
measured at $0,0.25,0.5,0.75,1,2,4,8,24,48,72,144$ or $288 \mathrm{~h}$.

\section{In vitro Cytotoxicity Study}

MTT (3-2,5-diphenyl-2-H-tetrazolium bromide) analysis was carried out according to the previous method. ${ }^{23}$ The L929 fibroblast cell line obtained from ATCC was grown in Dulbecco's modification of Eagle's medium (DMEM) containing fetal bovine serum $(10 \%), 50 \mathrm{U} / \mathrm{mL}$ penicillin, $50 \mathrm{U} / \mathrm{mL}$ streptomycin. ${ }^{24}$ Briefly, $10^{4}$ cells were seeded into a 96-well tissue culture plate and cultured overnight in a $5 \% \mathrm{CO}_{2}$ incubator. The medium was then aspirated, and replaced with a medium containing a series of concentrations $(31.25-200 \mu \mathrm{g} / \mathrm{mL})$ of nanoparticles, based on the results of preliminary experiment. The cells were treated with nanoparticles for 24 hours. Subsequently, $10 \mu \mathrm{L}$ of MTT was added to each well containing $100 \mu \mathrm{L}$ of cell suspension, followed by incubation at $37^{\circ} \mathrm{C}$ for 4 hours. Next, the reaction mixture was carefully removed and 200 $\mu \mathrm{L}$ of dimethyl sulfone was added to each well and mixed using a pipette until uniform. After 10 minutes, the OD was measured at $490 \mathrm{~nm}$ using a Microplate Reader (BioRad 6.0, Bio-Rad Laboratories Inc., CA, USA). The control group also received treatment under the same conditions.

\section{In vitro Antibacterial Activity}

Minimum inhibitory concentration (MIC) and minimum bactericidal concentration (MBC) of the BZK nanoparticles: The antimicrobial activity was evaluated by the broth microdilution method described previously. ${ }^{25}$ Briefly, a stock solution of BZK nanoparticles was diluted to $6.25,12.5,25.0,33.3,50.0,66.7,100$ or $200 \mu \mathrm{g} / \mathrm{mL}$ and $20 \mu \mathrm{L}$ of each was combined with $180 \mu \mathrm{L}$ of a MRSA 252 bacterial suspension $\left(1.0 \times 10^{5} \mathrm{CFU} / \mathrm{mL}\right)$ in a 96-well microtiter plate (Costar 3599, Corning Inc., NY, USA) at $37^{\circ} \mathrm{C}$. After 24 hours of incubation, the OD at $595 \mathrm{~nm}$ (OD595) was read using a microplate reader (Bio-Rad 6.0, Bio-Rad Laboratories Inc., CA, USA). MIC is defined as the lowest concentration that induces a measurable OD value of at least 0.05 , at $595 \mathrm{~nm}$ after 24 hours of incubation. Subsequently, $2 \mu \mathrm{L}$ bacterial solution of each well was incubated on BHI agar medium at $37^{\circ} \mathrm{C}$ for 1 day, followed by the observation of the colony by eye. MBC is the lowest concentration of nanoparticles required to result in a colony forming unit (CFU) reduction of $>99.9 \%$.

\section{In vitro Anti-Biofilm Activity}

MRSA bacterial culture $\left(1.8 \mathrm{~mL}, 1 \times 10^{7} \mathrm{CFU} / \mathrm{mL}\right)$ was added to $0.2 \mathrm{~mL}$ of BZK nanoparticles $(3.33 \mu \mathrm{g} / \mathrm{mL})$ in each well of a 24 cell culture plate before adding the coverslip (Thermo Fisher technologies, Waltham, Ma, USA). The bacteria were incubated at $37^{\circ} \mathrm{C}$ for 24 hours and washed twice with 0.1 M PBS. To eliminate anti-biofilm activity, $2 \mathrm{~mL}$ of MRSA 252 bacterial culture $\left(1 \times 10^{7} \mathrm{CFU} / \mathrm{mL}\right)$ was grown in a 24 -well cell culture plate equipped with a TSB cover plate for 24 hours. The biofilm was cleared of PBS, and treated with $200 \mu \mathrm{L}$ of $5 \mathrm{mg} / \mathrm{mL}$ BZK nanoparticles for 9 hours. The presence of intact biofilm was evaluated by staining with $1 \mathrm{mg} / \mathrm{mL}$ crystal violet (Sangon Biotech of Shanghai Co., Ltd, Shanghai, China) for 10 minutes, followed by rinsing away excess stain with water, dissolving in $95 \%$ ethanol, and measuring the optical density (OD) by Bio Rad 6.0 (Bio-Rad Laboratories Inc., CA, USA) at $595 \mathrm{~nm} .{ }^{15}$

\section{Biofilms Surface Observation}

Biofilm samples were covered with cover slips in glutaraldehyde $\left(2.5 \%\right.$, overnight at $\left.4^{\circ} \mathrm{C}\right)$. The resulting sample disc was washed 3 times in distilled water, and then dehydrated using an ethanol series $(25,50,75,90 \%$ and $100 \%$, respectively) including 5 minutes of continuous washing in each ethanol solution, followed by critical point drying (Tousimis, Rockville, MD, USA). Finally, samples were coated with carbon and imaged under an accelerating voltage using an S-3400N SEM (Hitachi, Japan). ${ }^{26}$ The voltage used was $10 \mathrm{kV}$, and $200 \AA$ gold palladium was used for sputter coating. Under the highresolution AFM IPC-208B (Chongqing University manufacturer, Chongqing, China) analysis of Chongqing University, after the morphological changes of these biofilms were approved under the BZK aqueous solution and nanoparticles, a tungsten tip probe with the following conditions (force constant of $0.06 \mathrm{~N} / \mathrm{m}$, scanning area $(1230 \mathrm{~nm} \times 1230 \mathrm{~nm}))$. In addition to point-by-point scanning at room temperature, atomic force microscopy (AFM) can also be used to image a sample in click mode. G3DR software (Chongqing University manufacturer, Chongqing, China) was used calculate parameters including Kurtis (Rku) and skewness (Rsk), as well as the average roughness $(\mathrm{Ra})$, mean square roughness $(\mathrm{Rq})$ and average roughness $(\mathrm{Rz})$ 


\section{Cell Membrane Damage}

MRSA $252\left(1 \times 10^{6} \mathrm{CFU} / \mathrm{mL}\right)$ cultures were added to BZK nanoparticles suspended in water at a concentration of $3.33 \mu \mathrm{g} / \mathrm{mL}$, and incubated at $37^{\circ} \mathrm{C}$ for 24 hours before centrifuging at $6000 \times \mathrm{g}$ for $5 \mathrm{~min}$ utes at room temperature. ${ }^{27}$ After removal of the supernatant, the cells were washed three times with PBS before preparation for TEM (FEI TECNAI10, Philips Electron Optics, Holland).

\section{Evaluation of in vivo Wound Healing Efficacy}

We used female BALB/c mice (6-8 weeks, weight 18-22 g; Beijing BHK Company) as an animal model for woundhealing analysis. Prior to the development of a dorsal wound, mice were anesthetized and healed with isoflurane (Shanghai Yuyan Instruments Co., Ltd, Shanghai, China). Hair was removed using an electric shaver and depilatory cream (Veet, Reckitt Benckiser, France). Subsequently, a $1 \mathrm{~cm}^{2}$ biopsy punch was used to excise back skin to form a full-thickness wound. The wound care models were divided into four groups: BZK aqueous solution $(5 \mathrm{mg} /$ $\mathrm{mL})$. BZK nanoparticles $(5 \mathrm{mg} / \mathrm{mL})$, blank nanoparticles control treatment, and wound infection group $(n=6)$. All wound mice were infected bacterial suspension with $50 \mu \mathrm{L}$ of $2 \times 10^{9} \mathrm{CFU} / \mathrm{mL}$ MRS. After 24 hours of infection, in all cases except for the wound infection group and the wound group, mice were treated locally for 14 consecutive days. Treatment involved the application of $50 \mu \mathrm{L}$ of each solution to the skin wound area keeping for 30 seconds twice a day. Wound size reduction (WSR) was calculated as $\mathrm{WSR}=\mathrm{Wt} / \mathrm{W} 0 \times 100$, where $\mathrm{W} 0$ is the wound area at the initial time 0 and $\mathrm{Wt}$ is the wound area at the time $\mathrm{t}$.

\section{Reduction of Wound Bacterial Burden}

Bacterial burden in the wound was determined on days 1, 3, 5 and 7 post treatments. A swab was placed on the wound and then into $1 \mathrm{~mL}$ of sterile saline, based on the previous reported. ${ }^{28}$ The swab was swirled to release the bacteria into the liquid and after a 10-fold dilution with sterile saline, $5 \mu \mathrm{L}$ of the sample was applied to an MHA plate and incubated at $37^{\circ} \mathrm{C}$ for 24 hours. After incubation, the number of colonies was counted and the number of viable bacteria at the time of inoculation was calculated with an auto-colony counter (Shineso Science \& Technology Co., Ltd, Hangzhou, China).

\section{Pathological Section of the Wound Area}

Wound tissue was collected and fixed in 10\% formaldehyde for 24 hours after executing the mice under anesthesia, and then sealed with paraffin on the 7th day of the in vivo experiment. After embedding the sample in paraffin, a microtome was used to cut tissue sections $(5 \mu \mathrm{m})$. The sample was then fixed onto a glass slide and stained with hematoxylin and eosin (H\&E) to assess skin morphology and collagen formation. Samples were analyzed using an optical microscope (Olympus BX53, Olympus, Japan), the wound images and area (length $\times$ width) were captured digitally and calculated.

\section{Statistical Analysis}

All statistical analysis was performed via one-way analysis of variance or two-way analysis of variance. Graph Pad PRISM 5.0 (Graph Pad Software, Inc., La Jolla, California, USA) software was used for Bonferroni posthoc testing. Results with p-values less than 0.05 are considered statistically significant.

\section{Result \\ Development and Characterization of the Novel Nanoparticles}

In this work, chitosan and PLGA-functionalized nanoparticles loaded with benzalkonium bromide were designed and prepared, as shown in Figure 1. The drug payload, defined as $\%$ of encapsulated BZK by weight of nanoparticles, obtained was $0.5 \%$. The encapsulation deficiencies, calculated based on actual payload/intended payload $\times$ $100 \%$, were $57.9 \%$, and nanoparticles morphology is shown in Figure $2 \mathrm{~A}$ and $\mathrm{C}$. The images reveal that the nanoparticles were discrete, uniform, and exhibited a round shape. The TEM images show spherical shapes (Figure 2A). In SEM and AFM images (Figure 2B and C), the nanoparticles appear to be monodispersed and spherical, with no visible aggregation. The nanoparticles had an average diameter less than $300 \mathrm{~nm}$, and were independently scattered over the entire microscopic field. It has been noted previously that the shape of nanoparticles is determined by the stabilizing agent, which in this case is BZK. Nanoparticles observed in electron micrographs appeared smaller in size than their hydrodynamic size as measured via DLS. The BZK nanoparticles prepared here have a mean hydrodynamic diameter of $229.7 \pm 18.13 \mathrm{~nm}$, and a mean polydispersity index (PDI) of $0.218 \pm 0.03$, as shown in Figure 2D. The low PDI observed in this study indicates a high degree of uniformity in the size 


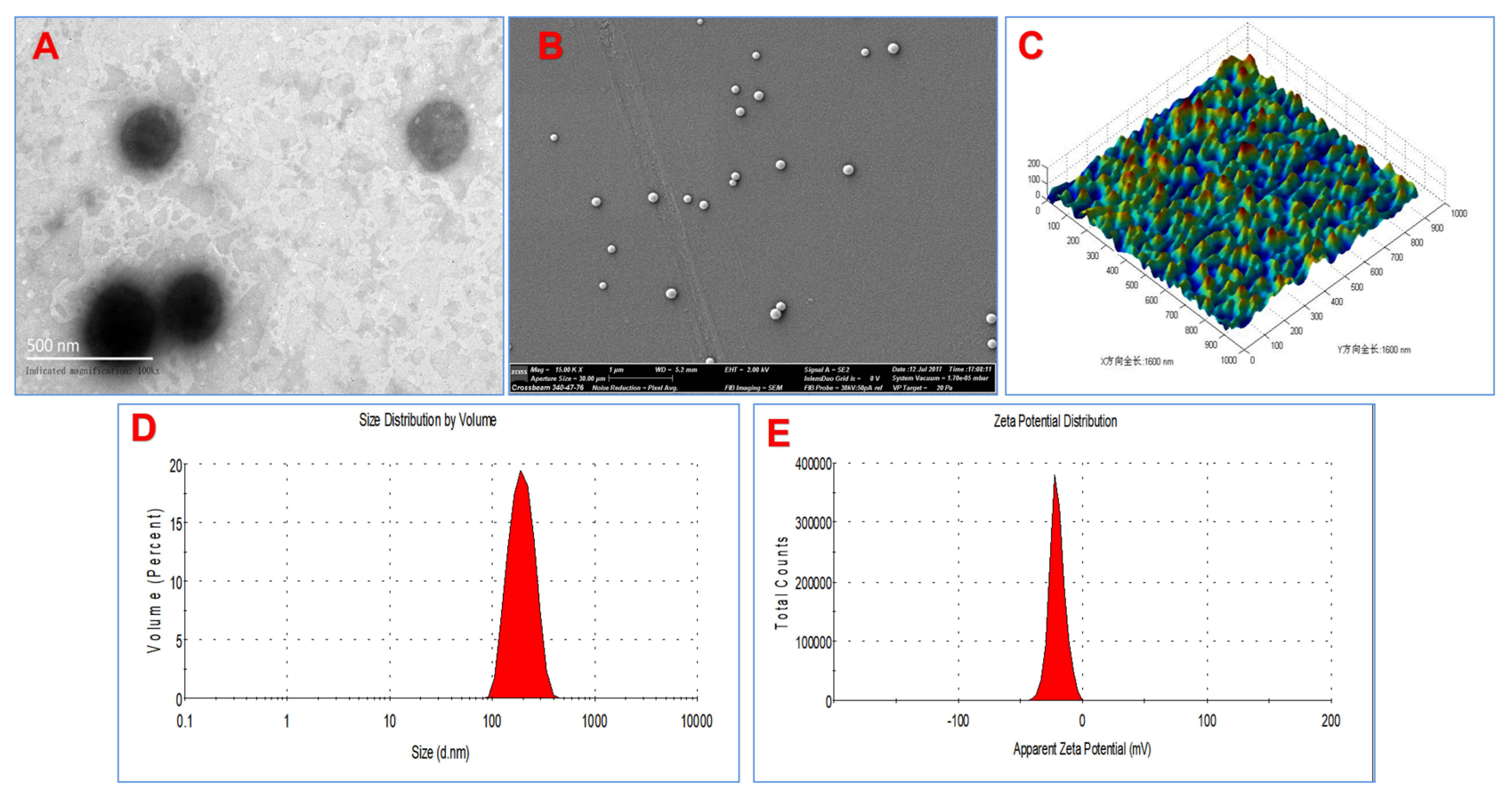

Figure 2 Characterization of PLGA nanoparticles. (A) TEM image of the BZK nanoparticles $(\times 100,000)$, (B) Scanning electron microscopy (SEM) images of the BZK nanoparticles ( $\times 15,000)$, (C) AFM images of the BZK nanoparticles for horizontal and morphologic analysis (X and Y scale bar I600 nm), (D) DLS particle size analysis of the BZK nanoparticles. (E) Zeta potential measurement of the BZK nanoparticles.

distribution. Zeta potential measurements showed that the BZK nanoparticles had a high negative surface charge value of $-23.4 \pm 0.085 \mathrm{mV}$ (Figure 2E), indicating moderate stability and no propensity for self-aggregation in colloidal suspensions. Overall, these nanoparticles have high negative zeta-potentials, which should indicate good stability.

\section{In vitro Release in the SWF Fluid}

The in vitro release profile of BZK nanoparticles, as well as their release kinetics and release mechanism, was studied in SWF. As depicted in Figure 3A, the release profile shows an initial fast release of nearly $90 \%$ of the BZK within the first 60 minutes, followed by a slow and sustained release reaching a maximum of $90 \%$ after $48 \mathrm{~h}$. In summary, relative to water solutions, the nanoparticles did not immediately disintegrate and release the active ingredient into the subcutaneous interstitial fluid through the skin; therefore, they exhibited a sustained-release mechanism.

\section{In vitro L929 Cell Toxicity}

The effect of BZK nanoparticles on L929 cells was studies in terms of cell viability, as depicted in Figure 3B. The results show that the nanoparticles induced a concentration-dependent decrease in cell viability under the conditions employed. Average cell viability after exposure to nanoparticles was recorded as $84.9 \pm 8.93 \%, 34.89$ $\pm 9.93 \%, 34.13 \pm 6.55 \%$, and $36.33 \pm 0.84 \%$ at $25,50,100$, and $200 \mu \mathrm{g} / \mathrm{mL}$ of nanoparticles, respectively, using the MTT assay. We found that blank nanoparticles control were nontoxic to the cells below a concentration of 100 $\mu \mathrm{g} / \mathrm{mL}$. In addition, the MTT assay showed that the increase in the number of cells over time, with all samples, was unaffected by the presence of the prepared nanoparticles suspended in Saline Solution and were thus deemed to be nontoxic to cells at concentrations below $25 \mu \mathrm{g} / \mathrm{mL}$.

\section{In vitro Antibacterial Activity}

The MIC of the novel BZK nanoparticles was determined for MRSA 252. Both the MIC and MBC values were measured to be $4.0 \pm 1.0 \mu \mathrm{g} / \mathrm{mL}$, while the water solution with the MIC of $5.0 \pm 2.0 \mu \mathrm{g} / \mathrm{mL}$ is the most effective, as shown in Figure $3 \mathrm{C}$ and $\mathrm{D}$. The MIC of an aqueous solution of BZK is 1.25 times that of the nanoparticles developed in this study. We also observed that blank nanoparticles have no obvious antibacterial effect. After treatment with its nanoparticles, the concentration was significantly different between 4.0 and $3.3 \mu \mathrm{g} / \mathrm{mL}$ $(p=0.0314, p<0.01)$. These results demonstrate that BZK 

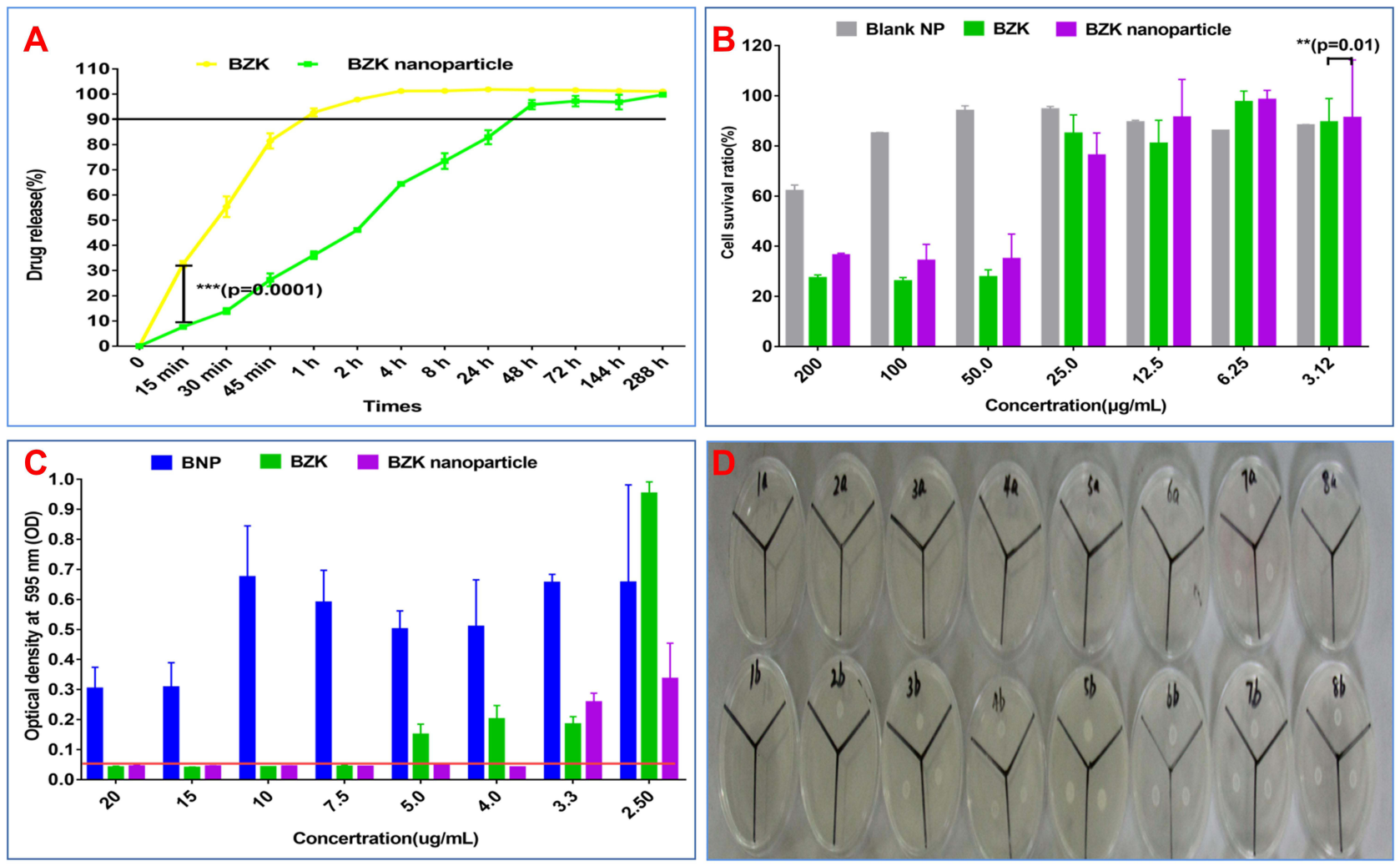

Figure 3 Nanoparticle release profile, measured in SWF, and antibacterial activity against MRSA in vitro. (A) Release profile of PLGA BZK nanoparticles (B) L929 cell toxicity of nanoparticles in vitro. (C) Minimum inhibitory concentrations (MICs). (D) MBC results from an investigation BZK treatment using the following concentrations of the Ia-8a is $20,15,10,7.55 .0,4.0,3.33,2.5 \mu \mathrm{g} / \mathrm{mL}$ of BZK nanoparticles, and Ib-8b is 20, I5, 10, 7.5 5.0, 4.0, 3.33, 2.5 $\mu \mathrm{g} / \mathrm{mL}$ of BZK water solution. Error bars represent mean \pm standard deviations of each experiment, conducted in triplicate.

Notes: $* * * p<0.001$ is an extremely significant difference, ${ }^{* *} p<0.01$ is a significant difference $(\mathrm{n}=3)$.

nanoparticles have greater antibacterial potential than its aqueous solution containing the active antibacterial agent alone.

\section{In vitro Anti-Biofilm Activity}

Crystal violet staining was used to semi-quantitatively evaluate the effect of BZK in aqueous solution, BZK nanoparticles, and blank nanoparticles (BNP) on MRSA 252 biofilm. Specifically, we evaluated the ability of these agents to limit biofilm formation, as well as their antibiofilm activity. Figure 4A shows that the ability of BZK nanoparticles to restrict MRSA biofilm formation in 24 hours at a concentration of $3.33 \mu \mathrm{g} / \mathrm{mL}$ is stronger than that of BZK in solution, at the same concentration. After 24 hours, the $\mathrm{OD}_{595}$ values of biofilm samples treated with aqueous BZK and BZK nanoparticles were 2.416 \pm 0.213 and $0.574 \pm 0.248$, respectively, revealing a 4.2 times reduction in biofilm formation for BZK nanoparticles. In Figure 4B and C, MRSA was treated with either a $3.33 \mu \mathrm{g} /$ $\mathrm{mL}$ BZK aqueous solution or BZK nanoparticles suspension, for 24 hours, followed by SEM analysis of physical and morphological changes. The biofilm in bacteria treated with nanoparticles (Figure 4C) is diffused and damaged, and the number of existing bacteria is obviously reduced. In addition, regarding the anti-biofilm activity of MRSA 252 biofilm formed under aqueous solution and BZK nanoparticles treated at $5 \mathrm{mg} / \mathrm{mL}$ for 4 hours, Figure 4D. The results show that the $\mathrm{OD}_{595}$ value of the sample treated with aqueous BZK is $1.963 \pm 0.11$, which is nearly 1.71 times larger than the value resulting from treatment with BZK nanoparticles (1.147 \pm 0.023$) \quad(p=0.0003$, $p<0.001)$. The morphology of bacteria in both BZK aqueous solution- and BZK nanoparticle-treated samples was examined by SEM, and it was found that the biofilm structure was scattered and damaged, and independently distributed in both cases (Figure 4E and F). SEM images of bacteria treated with BZK aqueous showed a similar morphology to those in the control group; however, the bacteria formed a dense network with nanoparticles (Figure 4F). It can be observed in the image that the 

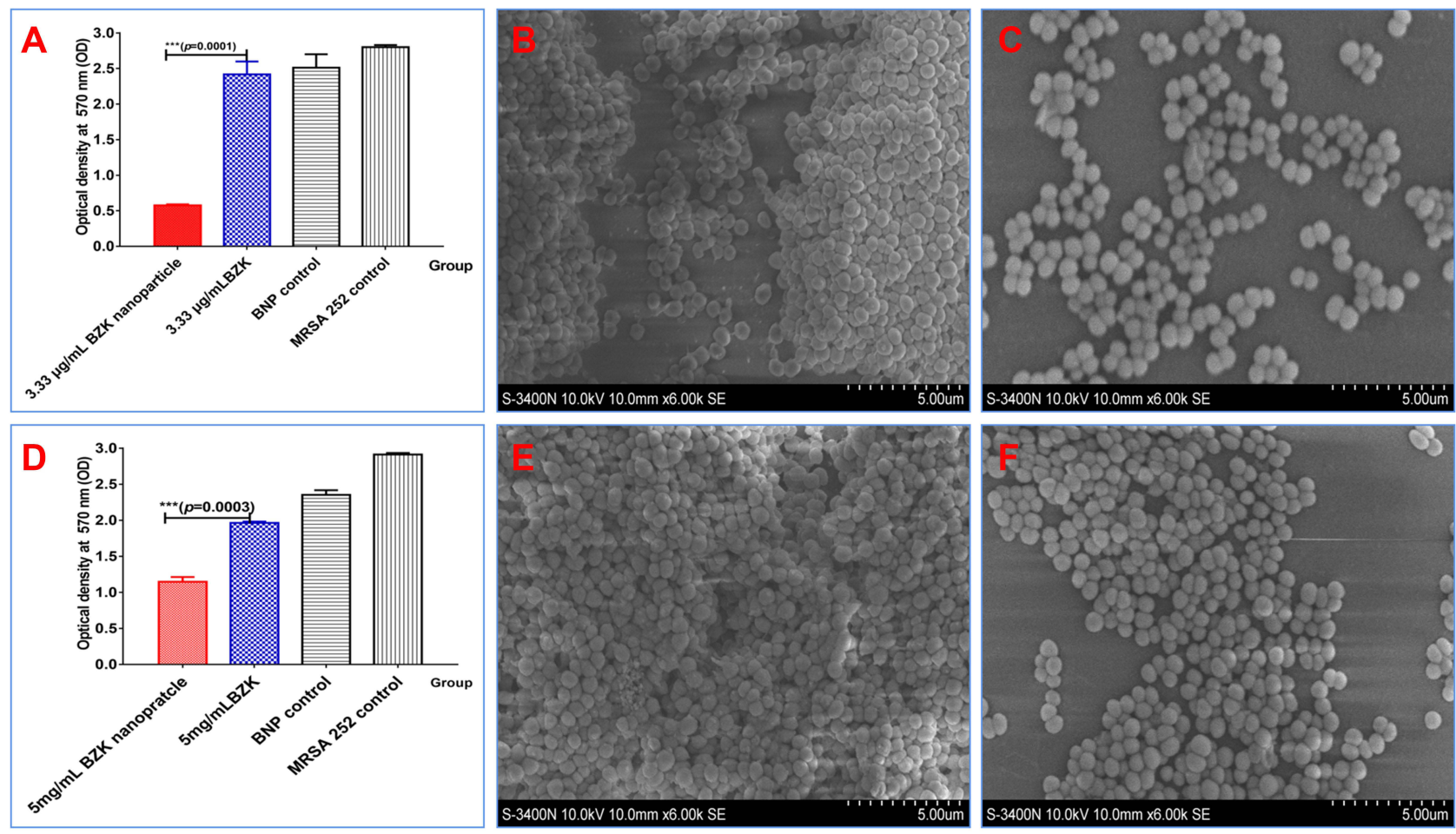

Figure 4 Reduction of formation and clearance of bacterial biofilms after BZK nanoparticles treatment. (A) Inhibition of biofilm formation using a $3.33 \mu g / m L$ BZK nanoparticles solution. (B) Biofilm surface structure after treatment with $3.33 \mu \mathrm{g} / \mathrm{mL}$ BZK aqueous solution ( $\times 6 \mathrm{k}$ magnification), (C) Biofilm surface structure after treatment with a $3.33 \mu \mathrm{g} / \mathrm{mL}$ BZK nanoparticles solution ( $\times 6 \mathrm{k}$ magnification) (D) Biofilm formation after treatment with a $5 \mathrm{mg} / \mathrm{mL}$ BZK nanoparticles solution. (E) Biofilm surface structure after treatment with $5 \mathrm{mg} / \mathrm{mL}$ of BZK in aqueous solution ( $\times 6 \mathrm{k}$ magnification) (F) Biofilm surface structure after treatment with a $5 \mathrm{mg} / \mathrm{mL}$ BZK nanoparticles solution ( $\times 6 \mathrm{k}$ magnification).

Notes: ${ }^{* * *} p<0.001$ is an extremely significant difference $(n=3)$.

thickness of nanoparticles of bacterial cell clusters is much smaller than these nanoparticles exposed to the same density of aqueous solution.

As shown in Figure $5 \mathrm{~A}$ and $\mathrm{B}$, the 3D structure of inhibiting biofilm formation is described by the average height and surface roughness of $3.33 \mu \mathrm{g} / \mathrm{mL}$ BZK-treated aqueous solution and nanoparticles after latent for 24 hours. Color images reveal that the average height of MRSA biofilm treated with aqueous BZK was higher than that of biofilms treated with BZK nanoparticles, for the same time duration and overall concentration of BZK. Average roughness (Rq), average roughness depth (Rz), and average roughness (Ra), as well as the measurement of kurtosis (Rku) and skewness (Rsk) of the biofilms are shown in the Figure $5 \mathrm{C}$ and $\mathrm{D}$. Taken together these results reveal that aqueous BZK can limit biofilm formation more effectively than BZK nanoparticles, under the conditions investigated here.

In Figure 5E and $\mathrm{F}$, the 3D structure of the biofilm was described by the average height and surface roughness after treatment with $5 \mathrm{mg} / \mathrm{mL}$ of BZK, in both aqueous and nanoparticle form, for 24 hours. Color images show that the average height of the remaining biofilm after treatment with aqueous BZK is greater than that resulting from treatment with BZK nanoparticles, using the same density of BZK and time duration. In addition, crosssectional parameters of interstitial organisms were measured, namely mean square roughness (Rq), average roughness depth (Rz), as well as the kurtosis (Rku) and skewness (Rsk) parameters, and the results are shown in Figure $5 \mathrm{G}$ and $\mathrm{H}$. As expected, the Rq, Rz, and Ra values for biofilms treated with both $3.33 \mu \mathrm{g} / \mathrm{mL}$ and $5 \mathrm{mg} / \mathrm{mL}$ of aqueous BZK are all larger than parameters obtained after treatment with BZK nanoparticles. The above data shows that BZK nanoparticles are more efficient in the inhibition and clearance of bacterial biofilms, than the corresponding treatment with an aqueous solution of BZK.

\section{Cell Membrane Damage}

Changes in cell membrane morphology of MRSA 252, after treatment with the aqueous solution and nanoparticles of BZK for $24 \mathrm{~h}$, were observed via TEM. TEM micrographs of MRSA that had not been exposed to BZK-treated and untreated bacteria (Figure 6A and B) revealed intact, multi- 


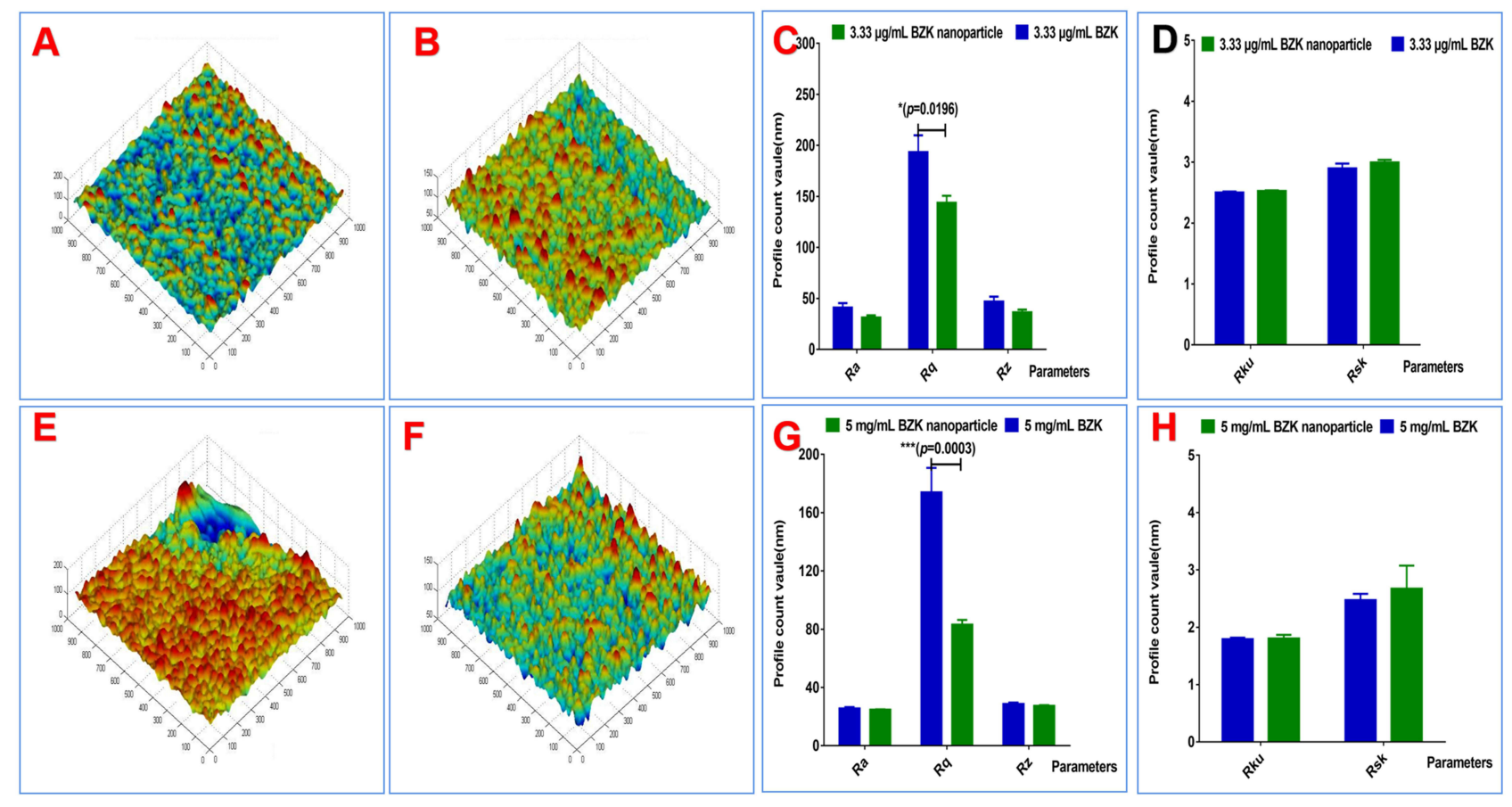

Figure $53 \mathrm{D}$ micrograph showing the inhibition and clearance of bacterial biofilms. (A) Micrograph of biofilm treated with a $3.33 \mu \mathrm{g} / \mathrm{mL}$ BZK aqueous solution (B) Micrograph of biofilm treated with a $3.33 \mu \mathrm{g} / \mathrm{mL}$ BZK nanoparticles solution. (C) Three profile parameters of biofilm treated with a $3.33 \mu \mathrm{g} / \mathrm{mL}$ BZK nanoparticles solution. (D) Two measurement parameters of biofilm treated with a $3.33 \mu \mathrm{g} / \mathrm{mL}$ BZK nanoparticle solution. (E) Micrograph of biofilm treated with $5 \mathrm{mg} / \mathrm{mL}$ BZK aqueous solution (F) Micrograph of biofilm treated with a $5 \mathrm{mg} / \mathrm{mL}$ BZK nanoparticles solution. (G) Three profile parameters of biofilm treated with a $5 \mathrm{mg} / \mathrm{mL}$ BZK nanoparticles solution. (H) Two measurement parameters of biofilm treated with a $5 \mathrm{mg} / \mathrm{mL}$ BZK nanoparticles solution.

Notes: $* * p<0.001$ is an extremely significant difference, $* p<0.05$ is a difference $(n=6)$
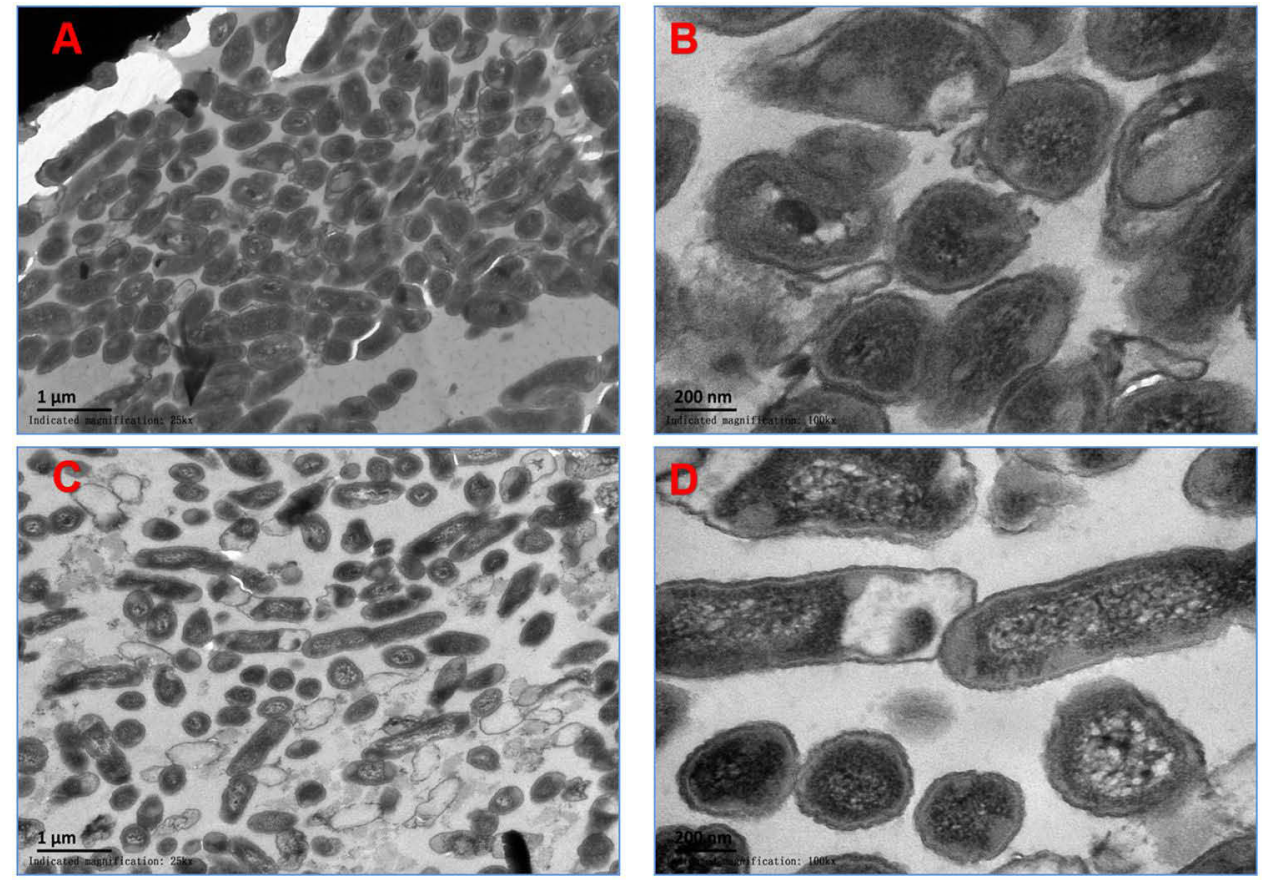

Figure 6 Cell membrane damage imaged via TEM. (A) MRSA treated with $3.33 \mu \mathrm{g} / \mathrm{mL}$ of BZK nanoparticles $(\times 25 \mathrm{k})$. (B) TEM images of MRSA treated with $3.33 \mu \mathrm{g} / \mathrm{mL}$ BZK aqueous solution $(\times 100 \mathrm{k}$ ). (C) TEM images of MRSA treated with $5 \mathrm{mg} / \mathrm{mL}$ of BZK nanoparticles $(\times 25 \mathrm{k})$. (D) TEM images of MRSA treated with $5 \mathrm{mg} / \mathrm{mL}$ of BZK nanoparticles $(\times 100 \mathrm{k})$. 
layer, cell membranes comprising the outer membrane, a peptidoglycan layer in periplasmic space, a cytoplasmic membrane and no signs of cell membrane damage. In both cases, the bacteria show a characteristic round shape, have a highly heterogeneous intracellular density corresponding to the DNA region, and have a complete wall with a welldefined membrane. Figure $6 \mathrm{C}$ and D shows that MRSA cells treated with the same concentration of BZK nanoparticles have cell membranes with altered morphology and signs of damage. The plasma membrane appears to be partially separated from the bacterial resulting in large vacuoles surrounding this area. In addition, the cytoplasm appeared contracted and the electron concentration was unevenly distributed within the cells. The cells also were abnormal in shape, and some cell skins were broken, which led to the release of cellular components such as proteins, electrolytes, nucleic acids, and intracellular enzymes.

\section{In vivo Wound Healing Efficacy}

The results of our in vivo healing study showed that the bacterial count in wounds treated with $5 \mathrm{mg} / \mathrm{mL}$ of BZK nanoparticles decreased faster, in comparison to wounds treated with the same concentration of aqueous BZK solution (Figure 7A). After 3 days of treatment, the number of bacteria in wounds treated with $5 \mathrm{mg} / \mathrm{mL}$ of BZK nanoparticles decreased by $38 \%$, while the decrease in the number of bacteria in wounds treated with $5 \mathrm{mg} / \mathrm{mL}$ of aqueous BZK solution was only $21 \%$. By the seventh day after treatment, the number of bacteria in wounds treated with $5 \mathrm{mg} / \mathrm{mL}$ of nanoparticles was decreased by $80 \%$, while the number of bacteria in wounds treated with $5 \mathrm{mg} /$ $\mathrm{mL}$ of aqueous BZK solution decreased by only $56 \%$. These data indicate that BZK nanoparticles can effectively reduce the local bacterial burden in wounds.

Blank nanoparticles infected with MRSA and wound area of BZK mice (Figure 7B-I, Figure 7B-IV). In contrast, infected mice showed normal wounds, without ulceration (Figure 7B-II). For wounds treated with $5 \mathrm{mg} / \mathrm{mL}$ of BZK nanoparticles, a scab formed and began to fall off (Figure 7B-III). The wound healing process was used to determine the healing properties of the novel BZK nanoparticles. As shown in Figure 7B and C, nanoparticles had a significantly higher cure rate than BZK in aqueous form. From the 7th day post treatment, the healing rate observed for wounds treated with $5 \mathrm{mg} / \mathrm{mL}$ of BZK nanoparticle was higher $(55.5 \%)$ than those treated with $5 \mathrm{mg} / \mathrm{mL}$ of aqueous BZK (50.7\%). In comparison with the above BZK-treated groups, wounds treated with blank nanoparticles (47.54\%) exhibited
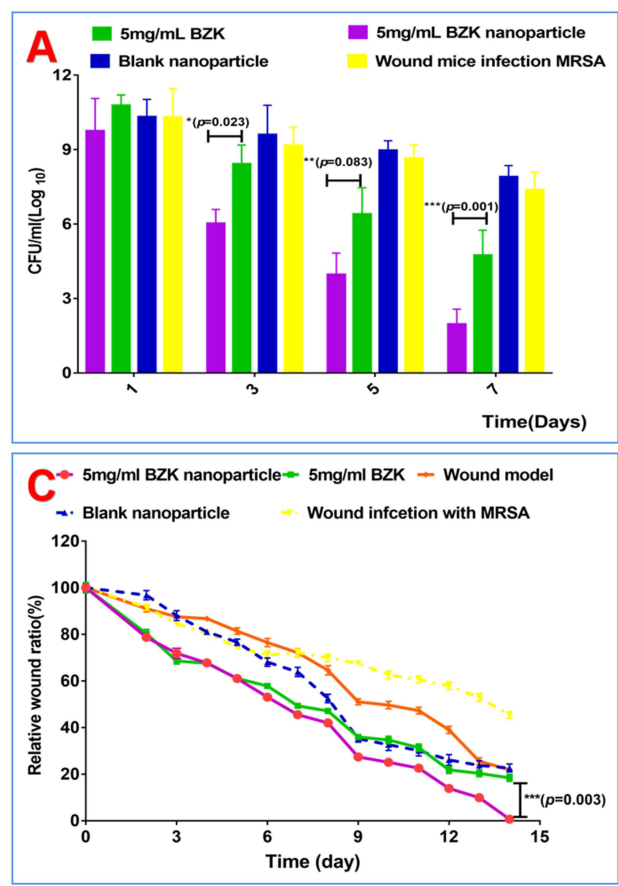
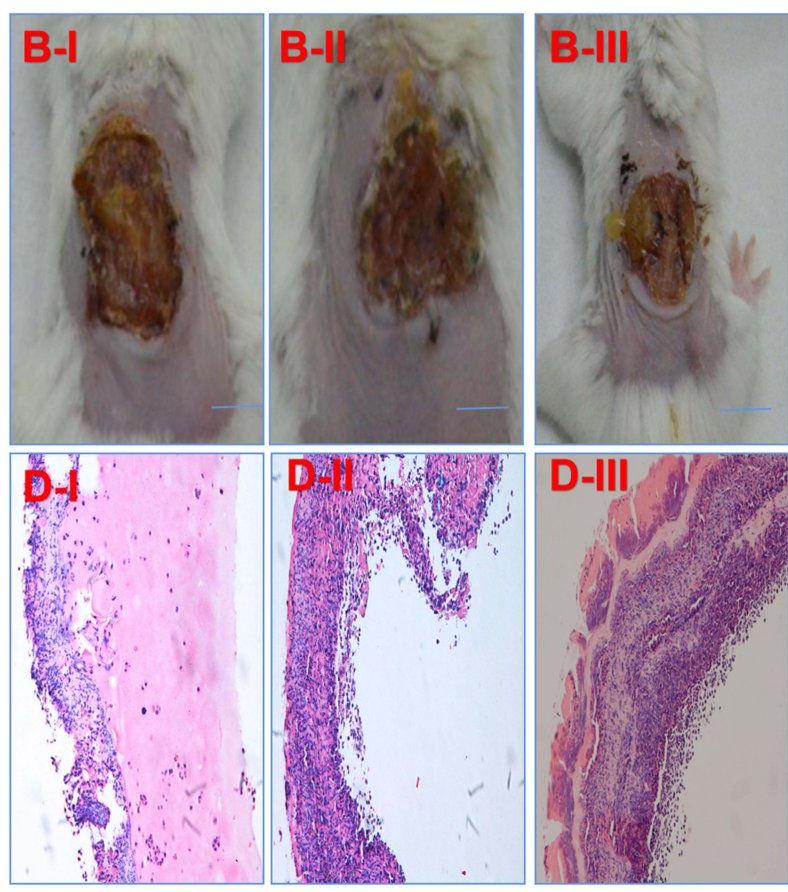
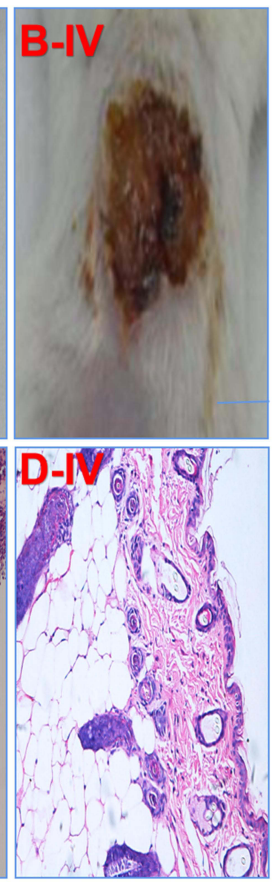

Figure 7 Antibacterial activity against MRSA infection in vivo. (A) Bacterium burden on days of I, 3, 5, and 7 post wounding; (B) I-IV. Images of wounds without treatment, treated with BZK water solution, BZK nanoparticles, and blank nanoparticles (scale bar, I cm). (C) Relative cure area ratio of the wound. (D) I-IV. Histological microscopic images of wounds without treatment, treated with a water solution, BZK nanoparticles, and blank nanoparticles $(\times 100$, scale bar: $100 \mu \mathrm{m})$. Notes: ${ }^{* * *} p<0.001$ is an extremely significant difference, ${ }^{* *} p<0.01$ is a significant difference, ${ }^{*} p<0.05$ is a difference $(\mathrm{n}=6)$ 
delayed healing; however, healing was still faster that the control group (30.08\%) after 3 days. Fourteen days after treatment, the extent of wound healing reached $100 \%$, $81.56 \%, 77.34 \%, 78.12 \%$, and $54.65 \%$ for the BZK nanoparticles, aqueous BZK, blank nanoparticle, control, and model infection groups, respectively (all $P<0.001$ ). These results indicate that BZK nanoparticles can improve the speed and extent of wound healing after MRSA infection.

Figure 7D I-IV shows the analysis of skin tissue from wound sites, for all groups, on day 7. Skin collected from all animals treated with BZK nanoparticles confirmed the establishment of full thickness wound, as well as the loss of normal epithelium, necrotic epidermis, and lower dermal fat. The muscle layer showed signs of infection and inflammation, and the inflammatory cell layer was dense. Inflammation became more obvious in the blank nanoparticle control group on the 7 th day, and remained on the higher side on the 7 th day of infection. In contrast with the control group, the number of inflammatory cells and epithelial formation in the BZK nanoparticle treatment group decreased after the 7 th day. Epithelial formation in the control group was poor, and the presence of neutrophils indicated that the MRSA infection persisted beyond the 7th day; however, at this stage, well-arranged epithelial formation, fewer inflammatory cells, and normal dermal collagen were observed. Skin tissues collected from BZK treatment groups on the 7th day showed remarkable wound healing, with well-arranged epithelium and hair follicles in newly formed skin tissue, and negligible neutrophil counts in the lower dermal layer. These results confirm the positive therapeutic effect of BZK preparations, and the results are positively correlated with the bacterial load observed in infected wounds.

\section{Discussion}

Wound healing is a major health-care challenge that poses a substantial financial and logistical burden on health-care systems. ${ }^{29}$ The wound healing process may be delayed by many factors, which exposes patients to long-term inflammation, increased tissue destruction and necrosis. ${ }^{30}$ Due to numerous applications of nanoparticles in hospital settings, and their efficiency in preventing and treating wounds, burns, and infections, the development of nanoparticles for clinical applications is becoming increasingly promising. ${ }^{31}$ Nanoparticles have made remarkable progress in the delivery of antibacterial drugs, specifically those based on natural polymers, which represents a promising method for the encapsulation of antibiotics with the advantage of targeted delivery and controlledrelease characteristics that improve the pharmacokinetics and therapeutic index, as well as reduce or eliminate antibiotic resistance. $^{32}$ PLGA has been widely used as a drug carrier in tissue engineering applications, and can be used to prepare nanoparticles designed for drug release. ${ }^{33}$ Due to their ability to adjust the degradation characteristics and biocompatibility, nanoparticles can be prepared for the delivery of almost any type of drug. ${ }^{34}$ The antibacterial activity of chitosan, specifically against S. aureus, is well known. ${ }^{35}$ Therefore, in this study, we chose chitosan and PLGA as the structural components for the development of novel nanoparticles.

Our data show that the size of the nanoparticles is approximately $200 \mathrm{~nm}$, and using TEM, SEM, and AFM, the size distribution was shown to be narrow. The particle size observed under SEM and TEM is smaller than that obtained from DLS analysis. This discrepancy is related to the physical state of the nanoparticles during the measurement. Results Similar to the research report, the antibacterial property of nanomaterial is one of the main standards for countering the growing threat of microbial drug resistance. ${ }^{35}$

PLGA nanoparticles are released through the overall erosion of the structural matrix in aqueous environments and SWF. ${ }^{36}$ The release of BZK molecules from PLGA nanoparticles was accelerated by spontaneous hydrolysis and enzymatic degradation of the ester bonds in water. And, we found that BZK nanoparticles have delay release profile in simulated wound fluid. This feature resulted in a high antibiotic concentration in the micro-environment around the cell surface, which greatly improved the antibacterial activity, in comparison with direct application approaches. In fact, the results show that the MIC value is reduced by a factor of 4 times. $^{37}$

Similarly, an enhancement in the antibacterial properties of nanoparticles comprised of chitosan has been observed in other studies. We believe that the BZK nanoparticles developed here have remarkable bactericidal effects due to their high affinity for surface-exposed active groups in microbial strains, and because the surfactant ions released by the nanoparticles can destroy bacterial cell membranes, resulting in cell death. Our results are similar to those of free chitosan, which is thought to destroy cell membranes. $^{38}$ Recent reported that S-nitrosoglutathione, Platensimycin or teicoplanin-PLGA nanoparticles as an ideal nanoparticles formulation for the treatment of 
MRSA-infected cutaneous wounds. ${ }^{9,37,39}$ And PLGA nanoparticles have non-toxic characteristics of biocomposite to normal tissue or cell line. ${ }^{40,41}$

One of the most troublesome aspects of wound healing is the adhesion and colonization of biofilm. Biofilm is a bacterial community that produces a protective extra cellular matrix, which is particularly persistent. The removal of a bacterial biofilm usually requires a factor of 100-1000 times higher local concentration of an antibiotic, in comparison to the bacterial strain alone. ${ }^{35}$ Biofilm formation is the most important virulence factor for MRSA infection, because the associated yeast cells will fall off the biofilm, resulting in a serious MRSA infection. In addition, MRSA can steadily increase the formation of bacterial biofilms. ${ }^{42}$ Our results show that BZK nanoparticles can effectively inhibit the formation of bacterial biofilms, and have the ability to remove existing biofilms, thus promoting the efficient healing of skin wounds. Inflammation of skin wounds often occurs in mice. ${ }^{31}$ This study has established that BZK nanoparticles coated with PLGA have a significant antibacterial effect on MRSA-challenged inflammation, both in vitro and in vivo, and effectively promote the healing of skin wounds. This result is consistent with previous studies using skin wound infection models. ${ }^{43}$

\section{Conclusion}

In the current study, we reported the preparation of the novel chitosan and poly(D,L-lactide-co-glycoside) nanoparticles loaded with benzalkonium bromide (BZK). And also, this novel nanoparticles were found to have significant antibacterial activity $(P<0.01)$, both in vitro and in vivo test. The stronger anti-biofilm ability of the nanoparticles to inhibit the formation of bacterial biofilms, at a concentration of 3.33 $\mu \mathrm{g} / \mathrm{mL}$, and clear existing bacterial biofilms, at a concentration of $5 \mathrm{mg} / \mathrm{mL}$, compare with its water solution. In addition, significant damage to bacterial cell walls also was found, providing insight into the mechanism of antibacterial activity. We found that wound healing is accelerated upon treatment with BZK nanoparticles, which may provide a therapeutic substitute for current wound healing approaches. Our research on skin pathology of nanoparticles therapy and wound healing uses a mouse wound model with histological characteristics similar to skin wound.

\section{Acknowledgments}

This study was supported by Natural Science Foundation Project program of Chongqing CSTC (No.cstc2019jcyjmsxmX0042).

\section{Disclosure}

The authors declared that there is no conflict of interest.

\section{References}

1. Wijesooriya LI, Waidyathilake D. Antimicrobial Properties of nonantibiotic agents for effective treatment of localized wound infections: a minireview. Int $J$ Low Extrem Wounds. 2020;15 34734620939748. doi:10.1177/1534734620939748

2. Pinto AM, Cerqueira MA, Banobre-Lopes M, Pastrana LM, Sillankorva S. Bacteriophages for chronic wound treatment: from traditional to novel delivery systems. Viruses. 2020;12(2):235. doi: $10.3390 / \mathrm{v} 12020235$

3. Mirrezaei N, Yazdian-Robati R, Oroojalian F, Sahebkar A, Hashemi M. Recent developments in nano-drug delivery systems loaded by phytochemicals for wound healing. Mini Rev Med Chem. 2020;20(18):1867-1878. doi:10.2174/1389557520666200807133022

4. Orsu P, Matta S. Fabrication and characterization of carboxymethyl guar gum nanocomposite for application of wound healing. Int J Biol Macromol. 2020;164:2267-2276. doi:10.1016/j.ijbiomac.2020.07. 322

5. Mir M, Permana AD, Tekko IA, et al. Microneedle liquid injection system assisted delivery of infection responsive nanoparticles: a promising approach for enhanced site-specific delivery of carvacrol against polymicrobial biofilms-infected wounds. Int $J$ Pharm. 2020;587:119643. doi:10.1016/j.ijpharm.2020.119643

6. Galvao FO, Dantas F, Santos CRL, et al. Cochlospermum regium (Schrank) pilger leaf extract inhibit methicillin-resistant Staphylococcus aureus biofilm formation. $J$ Ethnopharmacol. 2020;261:113167. doi:10.1016/j.jep.2020.113167

7. Gordon O, Miller RJ, Thompson JM, et al. Rabbit model of Staphylococcus aureus implant-associated spinal infection. Dis Model Mech. 2020;13(7).

8. Alabresm A, Chen YP, Wichter-Chandler S, Lead J, Benicewicz BC, Decho AW. Nanoparticles as antibiotic-delivery vehicles (ADVs) overcome resistance by MRSA and other MDR bacterial pathogens: the grenade hypothesis. J Glob Antimicrob Resist. 2020;22:811-817. doi:10.1016/j.jgar.2020.06.023

9. Lee J, Kwak D, Kim $\mathrm{H}$, et al. Nitric oxide-releasing s-nitrosoglutathione-conjugated poly(Lactic-Co-Glycolic Acid) nanoparticles for the treatment of MRSA-infected cutaneous wounds. Pharmaceutics. 2020;12(7):618. doi:10.3390/pharmaceutics12070618

10. Song M, Xia W, Tao Z, et al. Self-assembled polymeric nanocarrier-mediated co-delivery of metformin and doxorubicin for melanoma therapy. Drug Deliv. 2021;28(1):594-606. doi:10.1080/ 10717544.2021.1898703

11. Ju X, Miao T, Chen H, Ni J, Han L. Overcoming Mfsd2a-mediated low transcytosis to boost nanoparticle delivery to brain for chemotherapy of brain metastases. Adv Healthc Mater. 2021;10(9): e2001997. doi:10.1002/adhm.202001997

12. Fulaz S, Devlin H, Vitale S, Quinn L, O'Gara JP, Casey E. Tailoring nanoparticle-biofilm interactions to increase the efficacy of antimicrobial agents against Staphylococcus aureus. Int $J$ Nanomedicine. 2020;15:4779-4791. doi:10.2147/IJN.S256227

13. Liu H, Qu X, Kim E, et al. Bio-inspired redox-cycling antimicrobial film for sustained generation of reactive oxygen species. Biomaterials. 2018;162:109-122. doi:10.1016/j.biomaterials.2017. 12.027

14. Zhang J, Yan Y, Li Y, Shen C, Zhang Y. Topical effect of benzalkonium bromide on wound healing and potential cellular and molecular mechanisms. Int Wound J. 2021. doi:10.1111/iwj.13555

15. Yang S, Yang Y, Cui S, et al. Chitosan-polyvinyl alcohol nanoscale liquid film-forming system facilitates MRSA-infected wound healing by enhancing antibacterial and antibiofilm properties. Int J Nanomedicine. 2018;13:4987-5002. doi:10.2147/IJN.S161680 
16. Kim JY, Jun JH, Kim SJ, et al. Wound healing efficacy of a chitosan-based film-forming gel containing tyrothricin in various rat wound models. Arch Pharm Res. 2015;38(2):229-238. doi:10.1007/ s12272-014-0368-7

17. Chen G, Yu Y, Wu X, Wang G, Ren J, Zhao Y. Wound healing: bioinspired multifunctional hybrid hydrogel promotes wound healing. Adv Funct Mater. 2018;28(33):1870233. doi:10.1002/adfm.201870233

18. Yan X, Fang WW, Xue J, et al. Thermoresponsive in situ forming hydrogel with sol-gel irreversibility for effective methicillin-resistant staphylococcus aureus infected wound healing. ACS Nano. 2019;13 (9):10074-10084. doi:10.1021/acsnano.9b02845

19. Feng Z, Su Q, Zhang C, et al. Bioinspired nanofibrous glycopeptide hydrogel dressing for accelerating wound healing: a cytokine-free, M2-type macrophage polarization approach. Adv Funct Mater. 2020;30(52):2006454. doi:10.1002/adfm.202006454

20. Liu W, Ou-Yang W, Zhang C, et al. Synthetic polymeric antibacterial hydrogel for methicillin-resistant staphylococcus aureus-infected wound healing: nanoantimicrobial self-assembly, drug- and cytokine-free strategy. ACS Nano. 2020;14(10):12905-12917. doi:10.1021/acsnano.0c03855

21. Elsewedy HS, Dhubiab BEA, Mahdy MA, Elnahas HM. Development, optimization, and evaluation of PEGylated brucine-loaded PLGA nanoparticles. Drug Deliv. 2020;27 (1):1134-1146. doi:10.1080/10717544.2020.1797237

22. Du X, Xue J, Jiang M, et al. A multiepitope peptide, rOmp22, encapsulated in chitosan-PLGA nanoparticles as a candidate vaccine against Acinetobacter baumannii infection. Int $J$ Nanomedicine. 2021;16:1819-1836. doi:10.2147/IJN.S296527

23. Devanesan S, Ponmurugan K, AlSalhi MS, Al-Dhabi NA. Cytotoxic and antimicrobial efficacy of silver nanoparticles synthesized using a traditional phytoproduct, asafoetida gum. Int J Nanomedicine. 2020;15:4351-4362. doi:10.2147/IJN.S258319

24. Hamida RS, Ali MA, Goda DA, Al-Zaban MI. Lethal mechanisms of nostoc-synthesized silver nanoparticles against different pathogenic bacteria. Int J Nanomedicine. 2020;15:10499-10517. doi:10.2147/ IJN.S289243

25. Gomez-Sequeda N, Ruiz J, Ortiz C, Urquiza M, Torres R. Potent and specific antibacterial activity against Escherichia coli O157:H7 and methicillin resistant Staphylococcus aureus (MRSA) of G17 and G19 peptides encapsulated into Poly-Lactic-Co-Glycolic Acid (PLGA) nanoparticles. Antibiotics. 2020;9(7).

26. Zhao IS, Xue VW, Yin IX, Niu JY, Lo ECM, Chu CH. Use of a novel 9.3-mum carbon dioxide laser and silver diamine fluoride: prevention of enamel demineralisation and inhibition of cariogenic bacteria. Dent Mater. 2021;37(6):940-948. doi:10.1016/j.dental.2021.02.017

27. Hamida RS, Ali MA, Goda DA, Khalil MI, Al-Zaban MI. Novel biogenic silver nanoparticle-induced reactive oxygen species inhibit the biofilm formation and virulence activities of Methicillin-Resistant Staphylococcus aureus (MRSA) strain. Front Bioeng Biotechnol. 2020;8:433. doi:10.3389/fbioe.2020.00433

28. Song Z, Sun H, Yang Y, et al. Enhanced efficacy and anti-biofilm activity of novel nanoemulsions against skin burn wound multi-drug resistant MRSA infections. Nanomedicine. 2016;12(6):1543-1555. doi:10.1016/j.nano.2016.01.015

29. Pandit AP, Koyate KR, Kedar AS, Mute VM. Spongy wound dressing of pectin/carboxymethyl tamarind seed polysaccharide loaded with moxifloxacin beads for effective wound heal. Int $J$ Biol Macromol. 2019;140:1106-1115. doi:10.1016/j.ijbiomac.2019.08.202
30. Amanat S, Taymouri S, Varshosaz J, Minaiyan M, Talebi A. Carboxymethyl cellulose-based wafer enriched with resveratrol-loaded nanoparticles for enhanced wound healing. Drug Deliv Transl Res. 2020;10(5):1241-1254. doi:10.1007/s13346-020-00711-w

31. Lustosa A, de Jesus Oliveira AC, Quelemes PV, et al. In situ synthesis of silver nanoparticles in a hydrogel of carboxymethyl cellulose with phthalated-cashew gum as a promising antibacterial and healing agent. Int J Mol Sci. 2017;18(11):2399. doi:10.3390/ijms18112399

32. Scolari IR, Paez PL, Musri MM, Petiti JP, Torres A, Granero GE. Rifampicin loaded in alginate/chitosan nanoparticles as a promising pulmonary carrier against Staphylococcus aureus. Drug Deliv Transl Res. 2020;10(5):1403-1417. doi:10.1007/s13346-019-00705-3

33. Malikmammadov E, Tanir TE, Kiziltay A, Hasirci V, Hasirci N. PCL and PCL-based materials in biomedical applications. J Biomater Sci Polym Ed. 2018;29(7-9):863-893. doi:10.1080/09205063.2017.1394711

34. Wei P, Xu Y, Gu Y, Yao Q, Li J, Wang L. IGF-1-releasing PLGA nanoparticles modified 3D printed PCL scaffolds for cartilage tissue engineering. Drug Deliv. 2020;27(1):1106-1114. doi:10.1080/ 10717544.2020.1797239

35. Kaur J, Kour A, Panda JJ, Harjai K, Chhibber S. Exploring endolysin-loaded alginate-chitosan nanoparticles as future remedy for Staphylococcal Infections. AAPS PharmSciTech. 2020;21 (6):233. doi:10.1208/s12249-020-01763-4

36. Zakeri-Milani P, Loveymi BD, Jelvehgari M, Valizadeh $\mathrm{H}$. The characteristics and improved intestinal permeability of vancomycin PLGA-nanoparticles as colloidal drug delivery system. Colloids Surf B Biointerfaces. 2013;103:174-181. doi:10.1016/j.colsurfb.2012.10.021

37. Ucak S, Sudagidan M, Borsa BA, Mansuroglu B, Ozalp VC. Inhibitory effects of aptamer targeted teicoplanin encapsulated PLGA nanoparticles for Staphylococcus aureus strains. World J Microbiol Biotechnol. 2020;36 (5):69. doi:10.1007/s11274-020-02845-y

38. Asghar MA, Yousuf RI, Shoaib MH, Asghar MA. Antibacterial, anticoagulant and cytotoxic evaluation of biocompatible nanocomposite of chitosan loaded green synthesized bioinspired silver nanoparticles. Int $J$ Biol Macromol. 2020;160:934-943. doi:10.1016/j.ijbiomac.2020.05.197

39. Liu X, Wang Z, Feng X, et al. Platensimycin-encapsulated poly(lactic-coglycolic acid) and Poly(amidoamine) dendrimers nanoparticles with enhanced anti-staphylococcal activity in vivo. Bioconjug Chem. 2020;31 (5):1425-1437. doi:10.1021/acs.bioconjchem.0c00121

40. Selvaraju S, Ramalingam S, Rao JR. Inorganic apatite nanomaterial: modified surface phenomena and its role in developing collagen based polymeric bio-composite (Coll-PLGA/HAp) for biological applications. Colloids Surf B Biointerfaces. 2018;172:734-742. doi:10.1016/j.colsurfb.2018.09.038

41. Grune C, Zens C, Czapka A, et al. Sustainable preparation of anti-inflammatory atorvastatin PLGA nanoparticles. Int J Pharm. 2021;599:120404. doi:10.1016/j.ijpharm.2021.120404

42. Kumar D, Banerjee T, Chakravarty J, Singh SK, Dwivedi A, Tilak R. Identification, antifungal resistance profile, in vitro biofilm formation and ultrastructural characteristics of Candida species isolated from diabetic foot patients in Northern India. Indian $J$ Med Microbiol. 2016;34(3):308-314. doi:10.4103/0255-0857.188320

43. Xu X, Hu Y, Zhang L-P, et al. Lactic-co-glycolic acid-coated methylene blue nanoparticles with enhanced antibacterial activity for efficient wound healing. RSC Adv. 2020;10(21):12304-12307. doi:10.1039/D0RA01034K 


\section{Publish your work in this journal}

The International Journal of Nanomedicine is an international, peerreviewed journal focusing on the application of nanotechnology in diagnostics, therapeutics, and drug delivery systems throughout the biomedical field. This journal is indexed on PubMed Central, MedLine, CAS, SciSearch ${ }^{\circledR}$, Current Contents ${ }^{\circledR} /$ Clinical Medicine, $^{\circ}$
Journal Citation Reports/Science Edition, EMBase, Scopus and the Elsevier Bibliographic databases. The manuscript management system is completely online and includes a very quick and fair peer-review system, which is all easy to use. Visit http://www.dovepress.com/ testimonials.php to read real quotes from published authors.

Submit your manuscript here: https://www.dovepress.com/international-journal-of-nanomedicine-journal 